\title{
Pan-pneumatocele of Paranasal Sinuses: A Rare Entity
}

\author{
Sumit Bansal ${ }^{1}$ Ashok Kumar Mahapatra ${ }^{1}$ \\ ${ }^{1}$ Department of Neurosurgery, All India Institute of Medical Sciences, \\ Bhubaneswar, Orissa, India \\ Indian J Neurosurg 2016;5:61-62. \\ Address for correspondence Dr. Sumit Bansal, MCh, Room No. 419, \\ Department of Neurosurgery, All India Institute of Medical Sciences, \\ Bhubaneswar, Orissa 751019, India \\ (e-mail: drsumitbansal@gmail.com).
}

\section{Abstract Keywords \\ - paranasal sinus \\ - pneumatocele \\ - headache}

Excessive enlargement of the paranasal sinuses is a rare entity with an uncertain etiology. It usually affects the frontal sinus, although any sinus can be pathologically enlarged. Authors describe a case with enlargement of all paranasal sinuses (panpneumatocele). To date, this is the first reported case of pan-pneumatocele of paranasal sinuses in the literature.

\section{Case Report}

A 28-year-old woman presented to our department with intermittent episodes of moderate headache. The pain was not accompanied by facial swelling. It was also not related to head position. No palpable or visually evident anatomic deformity was noted. Neurologic examination was normal. Computed tomography (CT) of the head was done, which revealed that all the paranasal sinuses were excessively enlarged and well connected to each other with presence of bony erosion. No other abnormality was found. To date, this is the first reported case of pan-pneumatocele of paranasal sinuses in literature.

Excessive enlargement of the paranasal sinuses is a rare entity with an uncertain etiology. It usually affects the frontal sinus, although any sinus can be pathologically enlarged. Terms such as pneumosinus dilatans, pneumatocele, ${ }^{1}$ hyperpneumatization, sinus ectasia, sinus hypertrophy, and aerocele have been used in the literature to describe a hyperpneumatized paranasal sinus. Urken et $\mathrm{al}^{2}$ classified sinus hyperpneumatization into three types. Hypersinus refers to an enlargement of a well-aerated
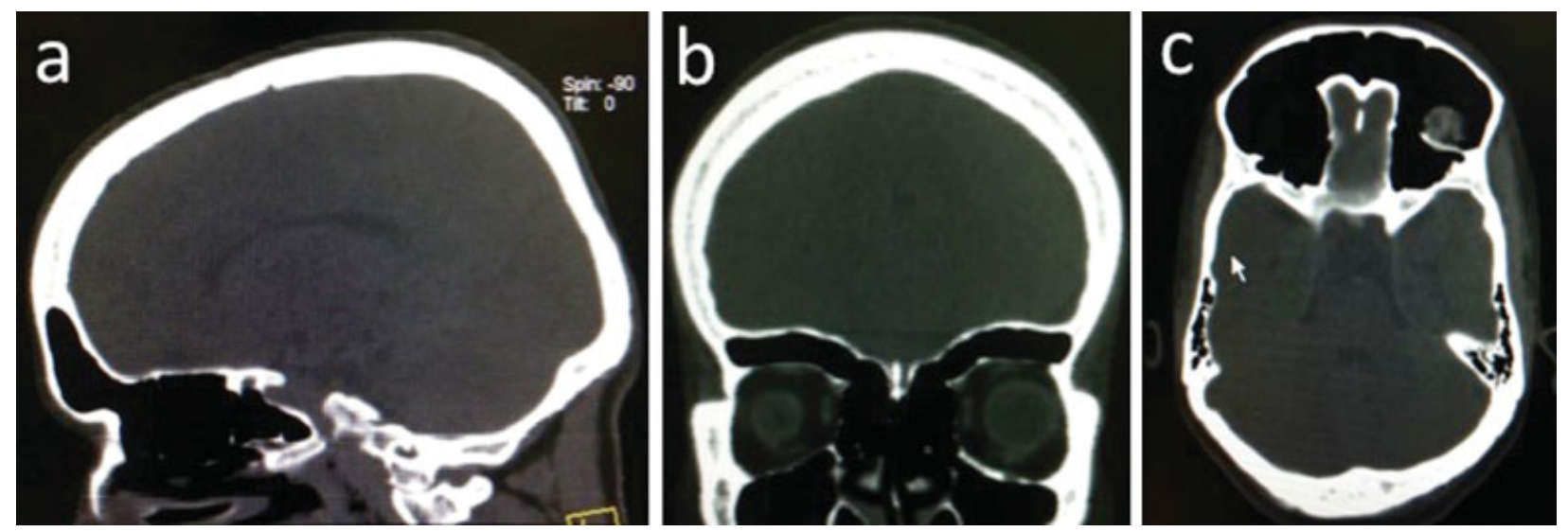

Fig. 1 Sagittal (a), coronal (b), and axial (c) views of CT of the head showing enlargement of all paranasal sinuses (frontal, ethmoid, maxillary, and sphenoid) along with bone erosion (pan-pneumatocele).

received

September 20, 2015 accepted

November 18, 2015

published online

February 24, 2016
DOI http://dx.doi.org/

10.1055/s-0036-1572377. ISSN 2277-954X. (c) 2016 Neurological Surgeons' Society of India

License terms

(ㄷ) (1) $\ominus$ (2) 
frontal sinus, which develops within the normal boundaries of the frontal bone. Pneumosinus dilatans differs from hypersinus because the sinus abnormally extends either anteriorly, causing frontal bossing, or posteriorly and laterally, displacing the adjacent anatomic structures, such as the ophthalmic bulb and the frontal lobe. A pneumatocele, the third type of hyperpneumatization, is characterized by focal erosion or generalized thinning of the bony walls, whereas in the first two types the sinus walls are normal. Although this classification was developed for the description of frontal sinus anatomic variations, it has been used in the literature for all paranasal sinuses. According to this classification, the present case is described as "pneumatocele of paranasal sinus" (-Fig. 1).

Hyperaeration itself may play a role in the development of headache symptoms, either by affecting the mucociliary clearance or due to disturbance of ventilation, which in turn causes vacuum headache. $^{3}$
Conflict of Interest

None.

Financial Support

None.

\section{References}

1 Abdel-Aal AK, Abayazeed AH, Raghuram K, Curé JK. Pneumocele of the frontal sinus producing orbital roof defect: case report and review of literature. Am J Otolaryngol 2010; 31(3):202-204

2 Urken ML, Som PM, Lawson W, Edelstein D, Weber AL, Biller HF. Abnormally large frontal sinus. II. Nomenclature, pathology, and symptoms. Laryngoscope 1987;97(5):606-611

3 Kalavagunta S, Reddy KTV. Extensive maxillary sinus pneumatization. Rhinology 2003;41(2):113-117 